AWARD NUMBER: $\quad$ W81XWH-13-1-0382

\title{
TITLE: TARGETING BREAST CANCER STEM CELLS IN TRIPLE NEGATIVE BREAST CANCER
}

PRINCIPAL INVESTIGATOR: RUBEN RENE GONZALEZ-PEREZ, Ph.D.

CONTRACTING ORGANIZATION: MOREHOUSE SCHOOL OF MEDICINE ATLANTA, GA 30310

REPORT DATE: OCTOBER 2014

TYPE OF REPORT: ANNUAL

PREPARED FOR: U.S. Army Medical Research and Materiel Command Fort Detrick, Maryland 21702-5012

DISTRIBUTION STATEMENT: Approved for Public Release;

Distribution Unlimited

The views, opinions and/or findings contained in this report are those of the author(s) and should not be construed as an official Department of the Army position, policy or decision unless so designated by other documentation. 


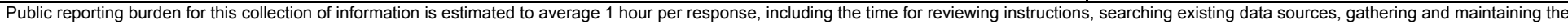

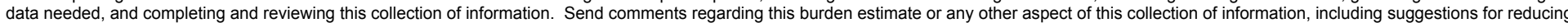

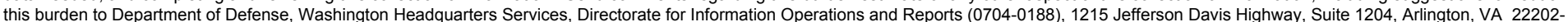

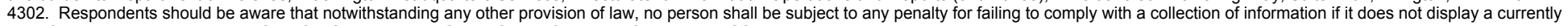
valid OMB control number. PLEASE DO NOT RETURN YOUR FORM TO THE ABOVE ADDRESS.
1. REPORT DATE
2. REPORT TYPE
ANNUAL
October 2014

4. TITLE AND SUBTITLE

TARGETING BREAST CANCER STEM CELLS IN TNBC

. DATES COVERED

30 Sep 2013 - 29 Sep 2014

5a. CONTRACT NUMBER

5b. GRANT NUMBER

W81XWH-13-1-0382

5c. PROGRAM ELEMENT NUMBER

6. AUTHOR(S)

RUBEN RENE GONZALEZ-PEREZ, Ph.D.

5d. PROJECT NUMBER

5e. TASK NUMBER

5f. WORK UNIT NUMBER

E-Mail: raonzalez@msm.edu

7. PERFORMING ORGANIZATION NAME(S) AND ADDRESS(ES)

8. PERFORMING ORGANIZATION REPORT NUMBER

AND ADDRESS(ES)

Morehouse School of Medicine

Atlanta, GA 30310-1495

9. SPONSORING / MONITORING AGENCY NAME(S) AND ADDRESS(ES)

10. SPONSOR/MONITOR'S ACRONYM(S)

U.S. Army Medical Research and Materiel Command

Fort Detrick, Maryland 21702-5012

11. SPONSOR/MONITOR'S REPORT

NUMBER(S)

\section{DISTRIBUTION / AVAILABILITY STATEMENT}

Approved for Public Release; Distribution Unlimited

\section{SUPPLEMENTARY NOTES}

\section{ABSTRACT}

Obesity is associated with higher incidence of triple negative breast cancer (TNBC) and drug resistance. We hypothesize that obesity effects on TNBC occur via leptin-signaling stimulation of breast cancer stem cells (BCSC), which could involve the activation of VEGFR-2/Notch axis. During the first year of the funding period we performed in vitro studies in human TNBC cell lines treated with leptin, and novel leptin receptor inhibitor bound to nanoparticles (IONPS-LPrA) alone, and combined with cisplatin (a chemotherapeutic) and Sunitinib (an inhibitor of VEGFR-2 kinase). Our data show that leptin increased cell proliferation and expression of BCSC markers in human TNBC that was accompanied by induction of mammosphere formation, reduced effectiveness of cisplatin and sunitinib and increased expression and activation of Notch.

\section{SUBJECT TERMS}

\begin{tabular}{|c|c|c|c|c|c|}
\hline \multicolumn{3}{|c|}{ 16. SECURITY CLASSIFICATION OF: } & \multirow{2}{*}{$\begin{array}{l}\text { 17. LIMITATION } \\
\text { OF ABSTRACT } \\
\text { Unclassified }\end{array}$} & \multirow{2}{*}{$\begin{array}{l}\text { 18. NUMBER } \\
\text { OF PAGES } \\
11\end{array}$} & \multirow{2}{*}{$\begin{array}{l}\text { 19a. NAME OF RESPONSIBLE PERSON } \\
\text { USAMRMC } \\
\text { 19b. TELEPHONE NUMBER (include area } \\
\text { code) }\end{array}$} \\
\hline $\begin{array}{l}\text { a. REPORT } \\
\text { Unclassified }\end{array}$ & $\begin{array}{l}\text { b. ABSTRACT } \\
\text { Unclassified }\end{array}$ & $\begin{array}{l}\text { c. THIS PAGE } \\
\text { Unclassified }\end{array}$ & & & \\
\hline
\end{tabular}


1. Introduction........................................................4

2. Keywords..............................................................4

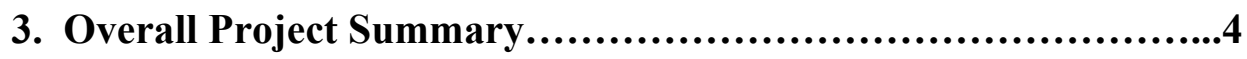

4. Key Research Accomplishments..................................10

5. Conclusion..............................................................10

6. Publications, Abstracts, and Presentations.........................10

7. Inventions, Patents and Licenses................................11

8. Reportable Outcomes..............................................11

9. Other Achievements..............................................11

10. References......................................................... 11

11. Appendices....................................................... 11 


\section{Introduction}

Obesity, a pandemic in the US, is associated with more than 100,000 incidents of cancer every year [1]. Obesity increases the risk for TNBC [2], which is three times more common in African American [16] that show higher incidence in pre-menopause age (39\%) when compared to patients of different ethnic background (16\%) [3]. Levels of leptin (the main adipokine secreted by adipose and breast cancer cells) are higher in obese individuals. Leptin induces the expression of Notch and several genes related to breast cancer stem cells (BCSC) maintenance, and could be involved in the induction of survival of TNBC treated with chemotherapeutics. We hypothesize that leptin's effects could involve the activation of a VEGFR-2/Notch axis. The elucidation of the molecular mechanisms by which BCSC survive in obese contexts may identify new targets for therapeutic intervention, for the "hard-to-treat" TNBC. During the first year of funded research, we investigated the effects of leptin on mammosphere formation by TNBC and expression of BCSC markers. Inhibition of leptin signaling using a novel inhibitor designed and produced by us, IONP-LPrA2, showed how leptin can contribute to TNBC resistance to chemotherapeutics (i.e., cisplatin and sunitinib).

\section{Key words}

Leptin, LPrA2, IONP-LPrA2, triple negative breast cancer, breast cancer stem cells, drug resistance, obesity-related breast cancer, Notch, VEGFR2.

\section{Overall Project Summary}

Task 1: Cell cultures and proliferation/BCSC/Apoptosis: human (MDA-MB231 and HC1806) and mouse TNBC (E0771-TAM will be cultured in vitro with leptin plus treatment.
a) Impact of treatment on Cell survival and Mammosphere formation.
b) Flow cytometry sorting/analyses of BCSC.
c) Apoptosis analysis.

To address the hypothesis we used a specific inhibitor of leptin signaling: leptin peptide receptor antagonist (LPrA2) coupled to nanoparticles, IONP-LPrA2 (receptor-targeted and near infrared dye labeled-magnetic iron oxide nanoparticles). Our data show that leptin increased the expression of BCSC markers in human MDA-MB231 cells (TNBC) that was accompanied by induced expression and activation of Notch and cell proliferation (Fig 1 $A-C)$. Leptin also induced $S$ phase progression, survival and expression of Notch in HCC1806 cells (TNBC; Fig 1D-F). These leptin's effects were abrogated by LPrA2 and IONP-LPrA2. 

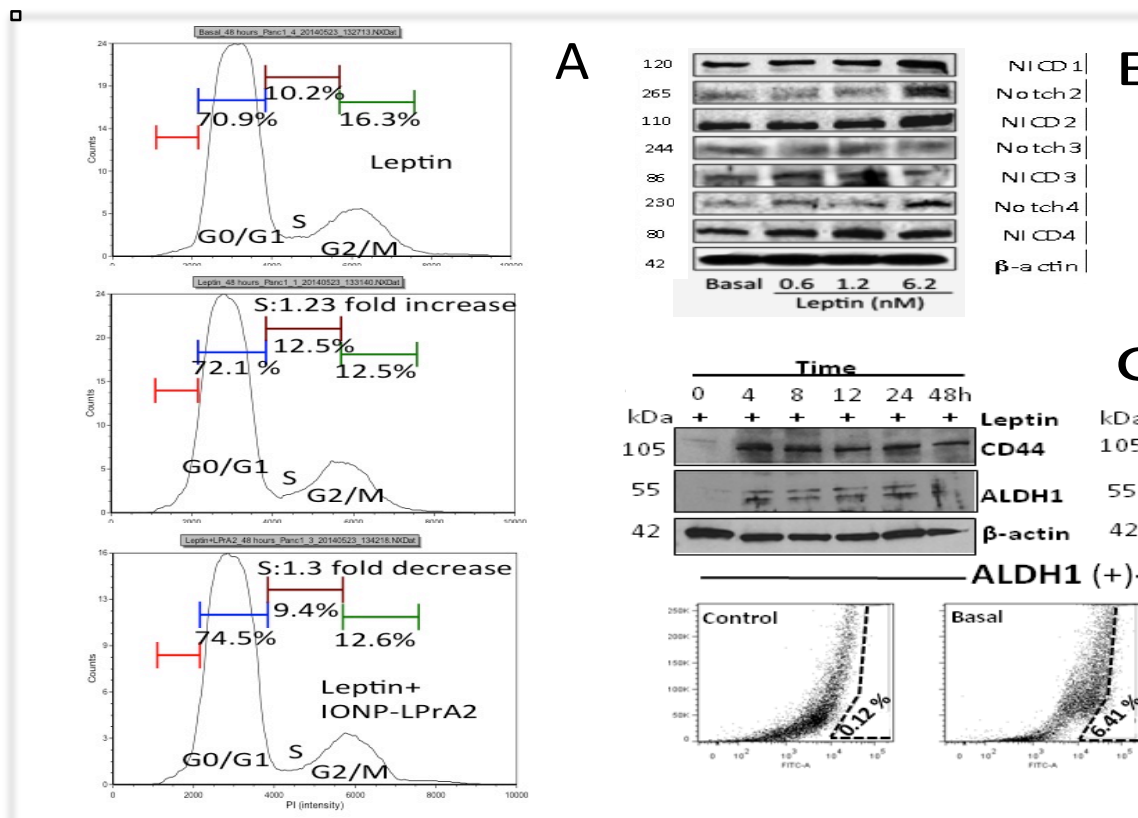

B
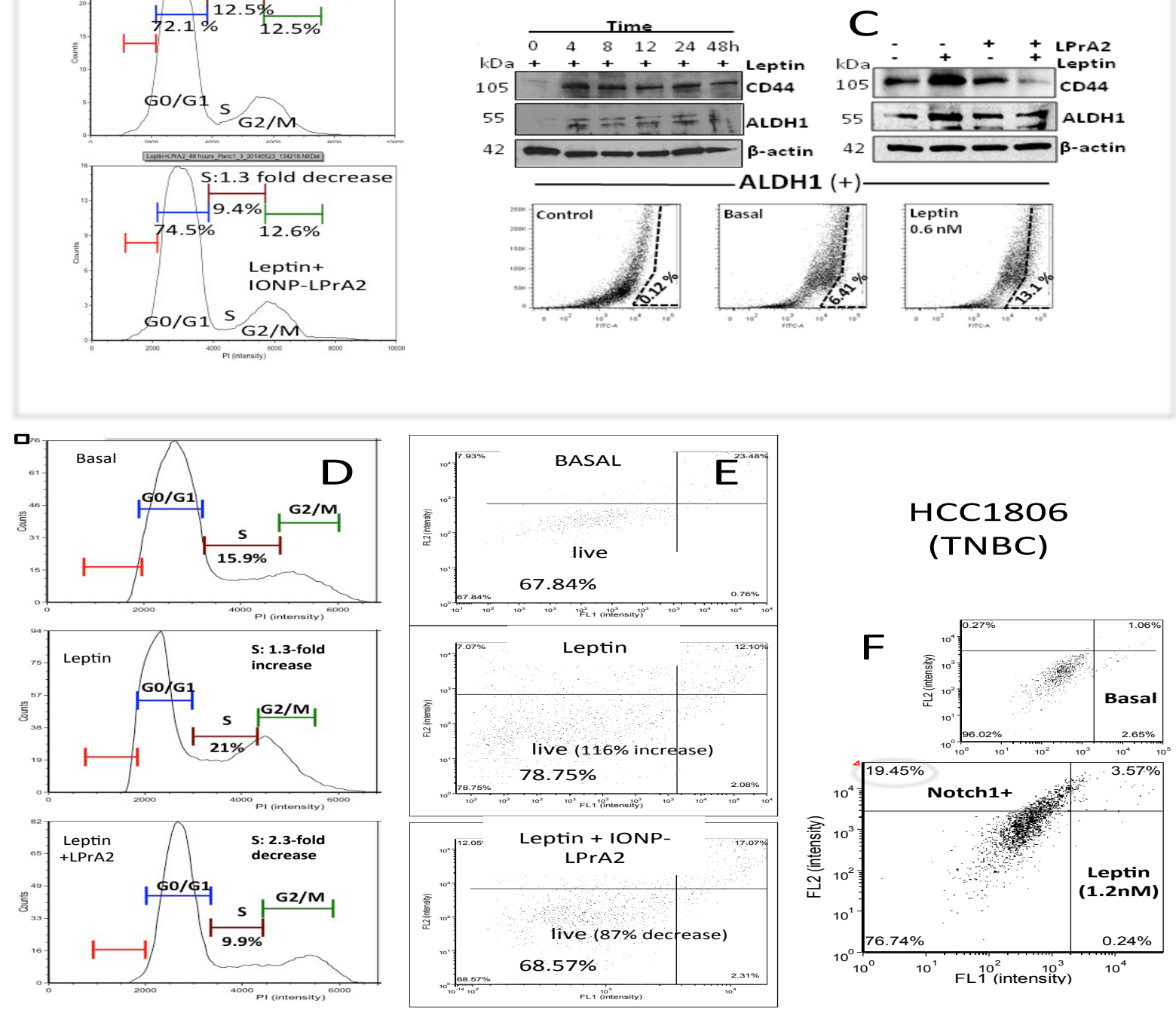

Fig 1. Leptin increased proliferation, survival and expression of BCSC markers and Notch in TNBC. In MDA-MB231 cells leptin induced: (A) Cell proliferation and S-phase progression, (B) Expression and activation of Notch, and (C) Expression of BCSC markers (CD44+ and ALDH1+) that was inhibited by LPrA2. In HCC1806 cells leptin induced: (D) S-phase progression and (E) cell survival, which were abrogated by LPrA2 and IONP-LPrA2, and (F) Expression of Notch1. (a): $\mathrm{p} \leq 0.05$. 
TNBC cells (MDA-MB231 and HCC1806) were cultures in medium containing FBS and treated with different doses of chemotherapeutics: sunitinib (a VEGFR2 inhibitor) and cisplatin (a $S$ phase inhibitor). In other series of experiments the cells received chemotherapeutic treatment plus IONP-LPrA2. Notably, the inhibition of leptin signaling via IONP-LPrA2 improved the efficacy of chemotherapeutics (Fig 2 and Table 1).

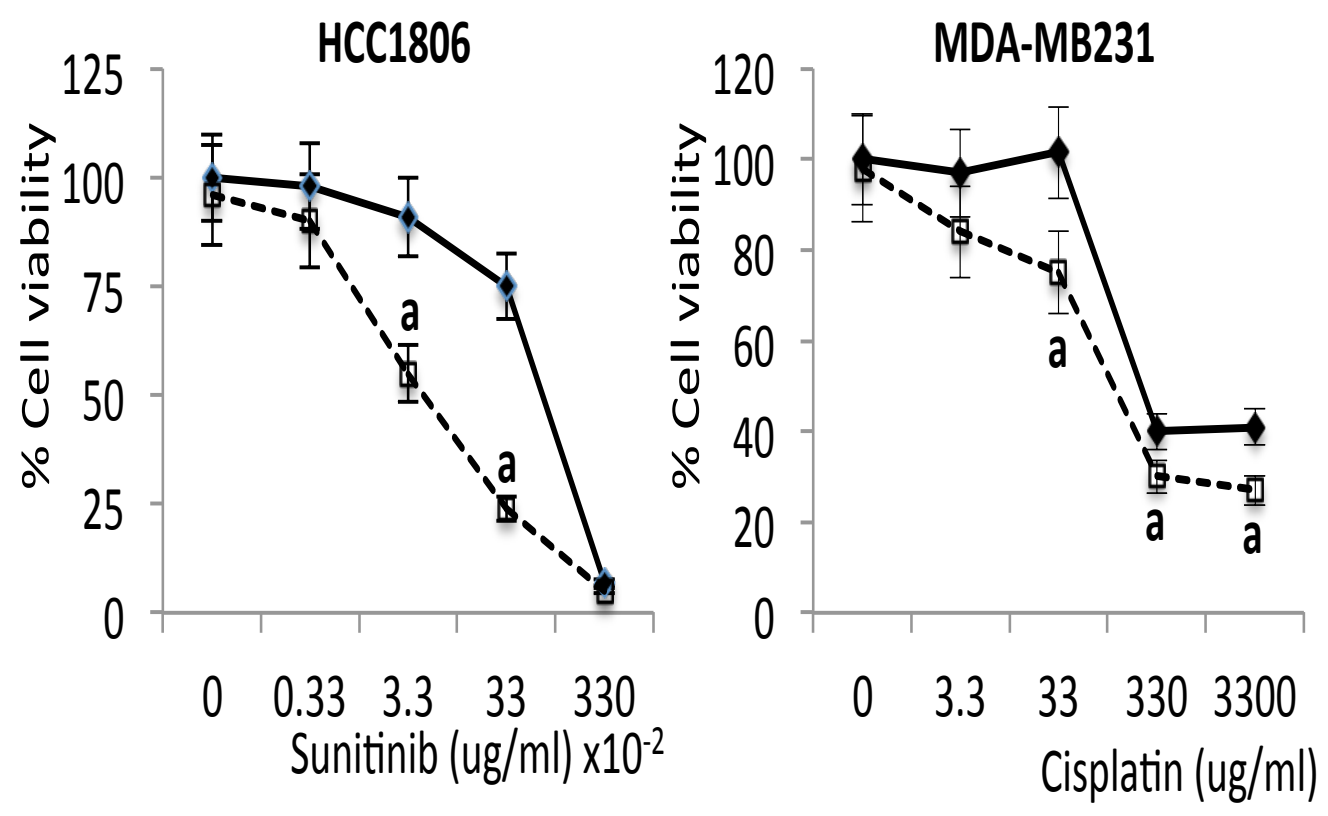

Fig 2. IONP-LPrA2 adjuvant treatment increased effectiveness of sunitinib and cisplatin in TNBC.

TNBC cells (HCC1806 and MDA-MB231) were cultured in medium containing FBS plus sunitinib and cisplatin (solid lines), and IONP-LPrA2 (dashed lines). Viability and apoptosis were determined by Annexin V/PI Cellometer assay. (a): $p<0.05$. 
Table 1. Leptin induces survival and reduces effectiveness of chemotherapeutics in HCC1806 cells. IONP-LPrA2 abrogates leptin's effects.

$\begin{array}{ccc} & \text { Live } & \text { Dead } \\ \text { BASAL } & 67.84 & 23.5 \\ \text { Lep } & 78.75 & 14.9 \\ \text { Lep+LPrA2 } & 68.57 & 17.07 \\ \text { Lep+Cis } & & \\ \text { Lep+Cis+LPrA2 } & 76.07 & 12.1 \\ \text { Lep+Sunitinib } & 31.2 & 45.19 \\ \text { Lep+Sunitinib+LPrA2 } & & \\ & 8.44 & 89.8 \\ \text { Lep+Cis+Sunitinib } & 6.84 & 90.7 \\ \text { Lep+Cis+Sunitinib+LPrA2 } & & \\ & 2.99 & 95.1 \\ & 2.99 & 95.1\end{array}$

Mammosphere formation: TNBC cells (MDA-MB231) single-cell suspensions were seeded at low density $(5,000-20,000$ cells $/ \mathrm{ml})$ in ultralow attachment dishes and cultured in specific tumorsphere medium (MammoCult medium; Stem Cells Technologies), supplemented with Hydrocortisone and Heparin [4]. Then, the cells were treated with 1.2nM leptin and 1.2nM Leptin+IONP-LPrA2 (dilution 1:5000) for two weeks [5]. Number of tumorspheres $(\geq 100 \mathrm{~nm})$ were assessed at weeks 1 and 2. Different tumorsphere sizes [small (<100um), medium (100200um) and large (>200um)] were also counted. Leptin increased total number of spheres that was abrogated by IONP-LPrA2 (Fig 3). Notably, leptin induced significant increase of medium size tumorspheres. Medium size tumorspheres decreased significantly when cells were treated with IONP-LPrA2 ( $p<0.05)$. 


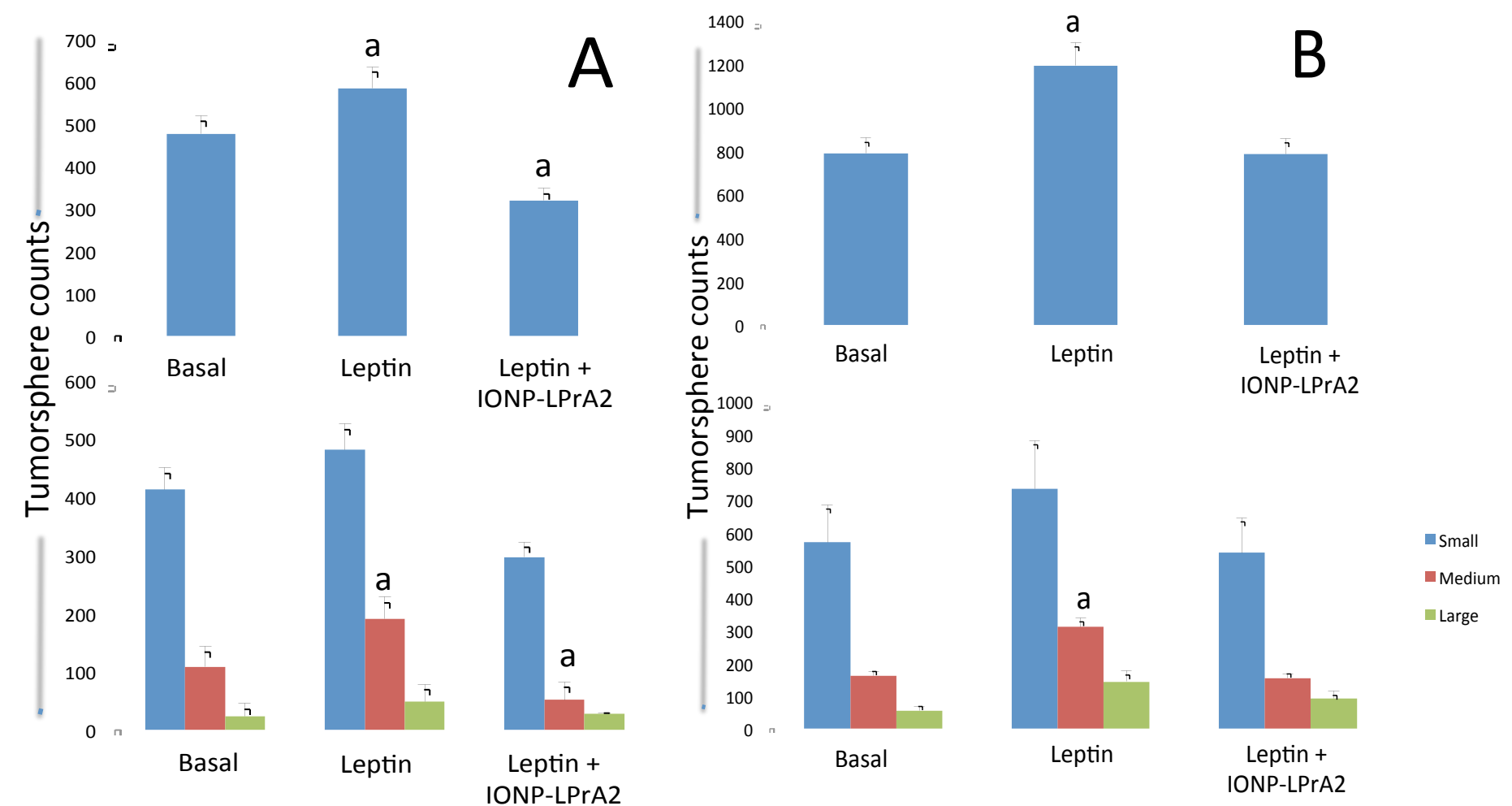

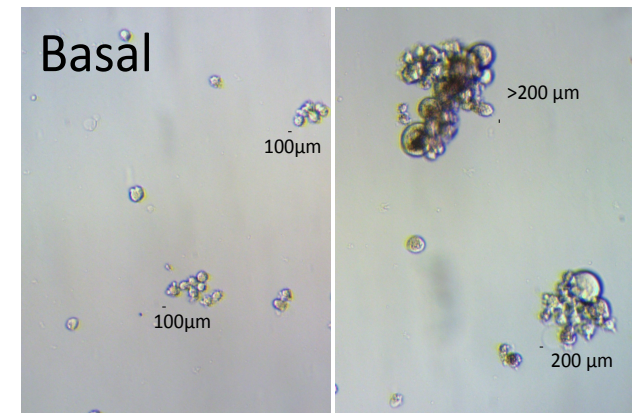

Tumor spheres: small (<100um), medium (100-200um) and large (>200um)

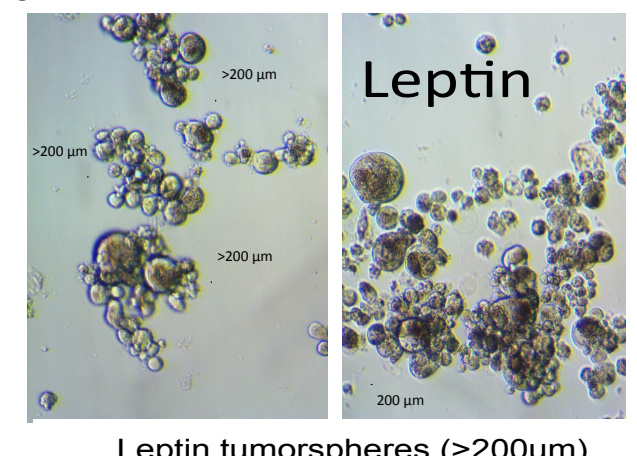

Leptin tumorspheres (>200um)

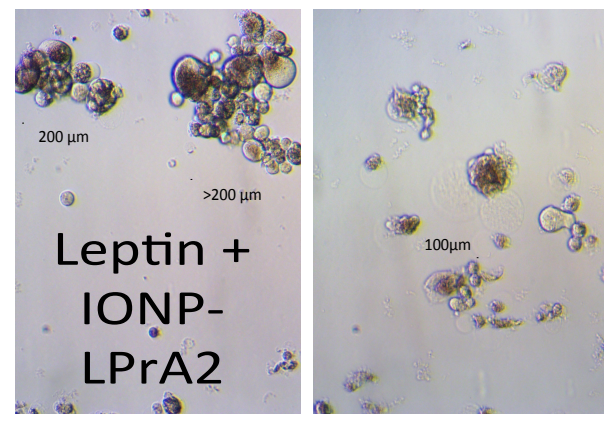

Leptin + IONP-LPrA2 tumorspheres

Fig 3. Leptin induced formation of tumorspheres in TNBC (MDA-MB231 cells) that was abrogated by IONP-LPrA2. Total tumorspheres and different sizes in basal medium, leptin 1.2 nM and IONP-LPrA2 plus leptin after one week (A) and two weeks (B). a: $p<0.05$ 


\section{Leptin-induction of breast cancer stem cell markers:}

After two weeks MDA-MB231 tumorspheres were disaggregated via enzymatic/mechanical techniques (Trypsin-EDTA) and the resulting single cell populations were analyzed using Nexcellometer for ALDH1 (ALDEFLUOR assay) and CD44+/CD24- expression [3].

Remarkably, leptin induced the expression of BCSC markers in MDA-MB231 cells from tumorspheres (see Fig 4). The number of double positive ALDH1/CD44 cells was increased by leptin (4x). However, IONP-LPrA2 completely abrogated leptin's effects.

\section{Basal}
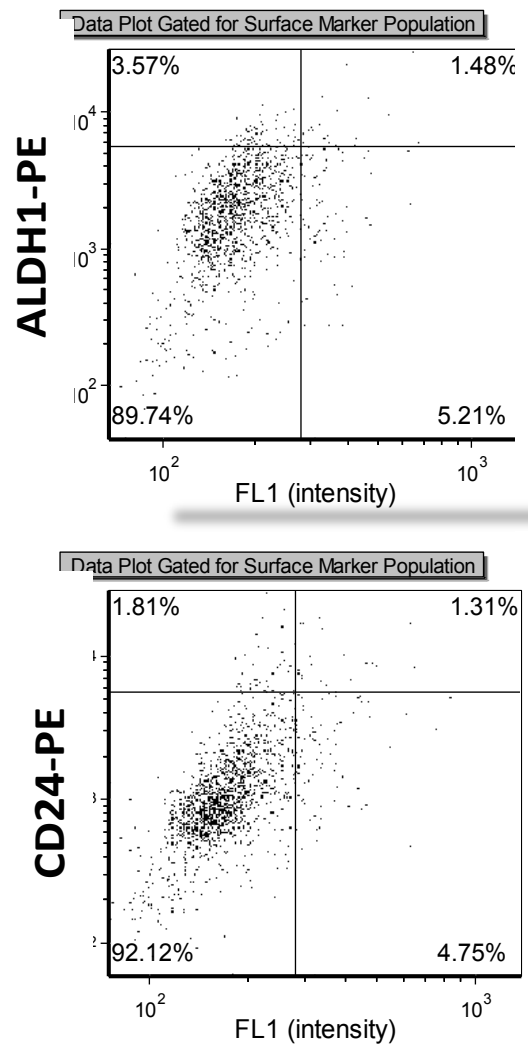

Leptin
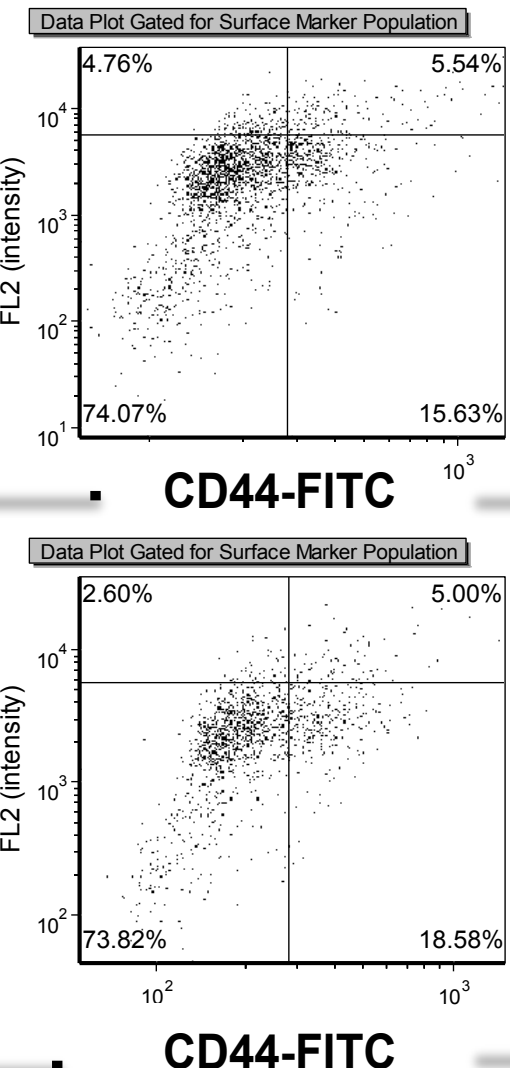
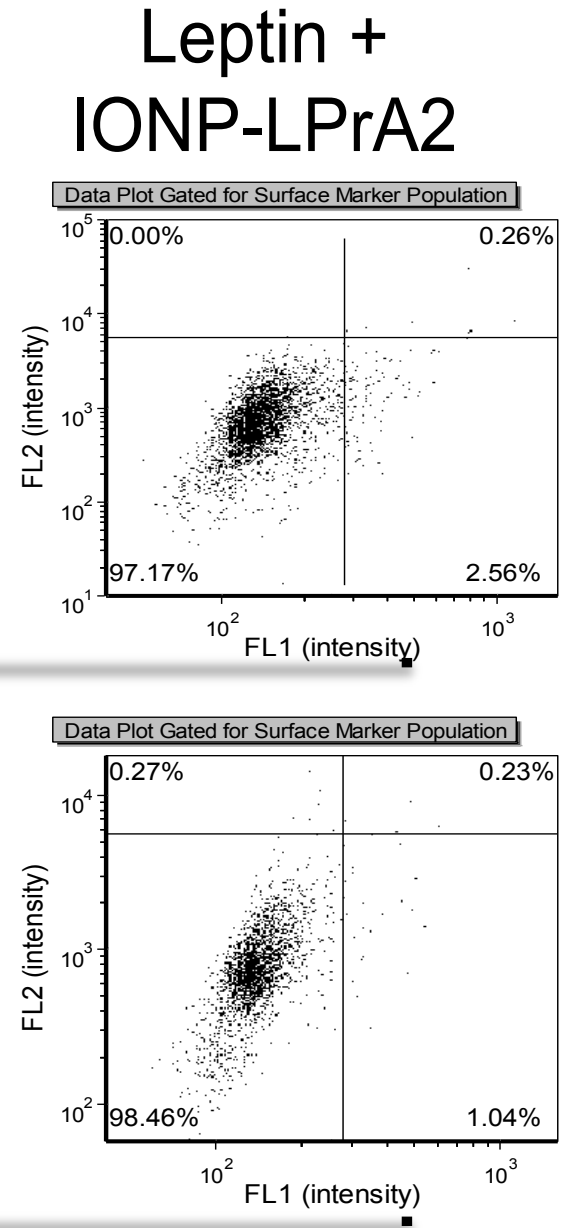

Fig 4. Leptin induced the expression of breast cancer stem cell markers (BCSC) in tumorspheres from MDA-MB231 cells. IONP-LPrA2 abrogated leptin's effects on BCSC. 


\section{Key Research Accomplishments}

1. Leptin increases survival of TNBC treated with cisplatin or sunitinib. Therefore, obesity signals (leptin) could affect chemotherapeutic efficacy.

2. IONP-LPrA2 abrogates leptin's effects on cell survival and synergized chemotherapeutic effects on TNBC in vitro. These data suggest that IONP-LPrA2 could be a novel adjuvant therapy for TNBC, particularly in obesity context. Moreover, IONP-LPrA2 adjuvant therapy could allow the reduction of chemotherapeutic dose.

3. Leptin induces the formation of tumorspheres from TNBC that was abrogated by IONPLPrA2.

4. Leptin upregulates the expression of breast cancer stem cell (BCSC) markers. Therefore, leptin could be a factor inducing BCSC that are believed responsible for the development of drug resistance in TNBC. Notably, IONP-LPrA2 inhibited leptin induction of BCSC.

\section{Conclusion}

Obesity correlates to higher incidence of TNBC and poor prognosis. However, the specific mechanisms for these relationships are unknown. Data generated suggest that leptin, the major adipokine secrete by adipose tissue and TNBC cancer cells, could be in part responsible for the observed link between obesity and TNBC. Leptin seems to induce TNBC proliferation, survival, tumorigenesis (tumorsphere formation) and BCSC, which are linked to increase development of chemotherapeutic resistance and relapse. Effective inhibition of leptin signaling in TNBC via novel IONP-LPrA2 nanoparticles could be a new adjuvant therapy for TNBC. IONP-LPrA2 could also allow reduction of chemotherapeutic dose, which is highly needed to diminish the undesirable devastating side effects of chemotherapeutics.

\section{Publications, Abstracts and Presentations}

1. Lanier V, Gillespie C, Dale-Brown D, Leffres M, Waltenberger, J, Gonzalez-Perez RR. Leptin induces a VEGFR2/Notch crosstalk in endothelial cells. New England Science Symposium, 2014, Joseph B. Martin Conference Center at Harvard Medical School, Boston, MA.

2. Harmon T, Harbuzariu A, Yang L, Gonzalez-Perez RR. Novel adjuvant therapy with leptin peptide receptor antagonist-2 conjugated to nanoparticles (IONP-LPrA2) to minimize chemoresistance in triple negative cancer". $26^{\text {th }}$ EORTC-NCI-ACR Symposium on "Molecular targets and Cancer therapeutics", Barcelona, Spain, 2014.

3. Harmon T, Harbuzariu A, Yang L, Gonzalez-Perez RR. Nanoparticles conjugated with the leptin peptide receptor antagonist 2 inhibit Notch expression in breast cancer. $\mathrm{NIH} / \mathrm{NCl} 2014$ International Symposium on Minority Health and Health Disparities, ISMHHD, NIH/NIMHD/DHHS. Baltimore, MD, 2014.

4. Harmon T, Harbuzariu A, Dill CD, Yang L, Gonzalez-Perez RR. Leptin Signaling Inhibition via IONP-LPrA2: a novel adjuvant therapy for Triple Negative Breast Cancer. San Antonio Breast Cancer Symposium, TX, 2014. 
Inventions, Patents and Licenses

"Nothing to Report"

Reportable Outcomes

"Nothing to Report"

Other Achievements

"Nothing to Report"

\section{References}

1. World Health Organization. 2014. http://www.who.int/mediacentre/factsheets

2. Pierobon $M$, Frankenfeld $C L$. Obesity as a risk factor for triple-negative breast cancer: a systematic review and meta-analysis. Breast Cancer Res Treat 2013, 137:307-314. PMID:23179600

3. Carey LA, et al. Race, breast cancer subtypes, and survival in the Carolina Breast Cancer Study. JAMA 2006, 295: 2492-2502. PMID:16757721

4. Cioce, M., et al., Mammosphere-forming cells from breast cancer cell lines as a tool for the identification of CSC-like- and early progenitor-targeting drugs. Cell Cycle, 2010. 9(14): p. 2878-87.

5. Yan, D., et al., Leptin-induced epithelial-mesenchymal transition in breast cancer cells requires beta-catenin activation via Akt/GSK3- and MTA1/Wnt1 protein-dependent pathways. J Biol Chem, 2012. 287(11): p. 8598-612.

\section{Appendices}

N/A 